\title{
Developing Competitive Strategies among Entrepreneurial Managers in Nigeria using DEMATEL Approach
}

\begin{abstract}
"Olamitunji Dakare
School of Mannigement and Social Sciences, Panl-Itlantic Iniversity, Ligos, ligeriia

The study is aimed at investigating how entrepreneurial managers in Nigeria can better identify and distinguish the cause-andeffect relationship amongst the components of competitive strategies. The components of competitive strategies among entrepreneurial ventures were classified into three components and eleven criteria after a review of the literature. The study applied the Decision-Making Trial and Evaluation Laboratory (DEMATEL) model to identify and describe the cause-and-effect relationship amongst the components of competitive strategies. The findings revealed that in prioritizing the importance of criteria and cause-and-effect relationship among criteria under the three core components, emphasis on being ahead of the competition, strong sales force and R\&D expenditure for process innovations were the most critical criteria. Furthermore, the findings have, however, showed that emphasis on being ahead of the competition was the most important criterion in the adjustment of components of competitive strategies among entrepreneurial ventures in Nigeria. Therefore, to develop a highly competitive strategy among entrepreneurial ventures, entrepreneurial managers will need first to develop the culture and attitude of being ahead of the competition in line with their managerial propensities which, in turn, will help them to create strategic moves that can give a high payoff in the midst of competitive pressures from rivals.
\end{abstract}

Keywords: Competitive strategy, capabilities, entrepreneurial ventures, Nigeria, DEMATEL

JEL $: M 13$

In most countries of the world, small and medium enterprises constitute 50 percent to 70 percent of employment sources, while they also play a pivotal role in accelerating socio-economic development (Duru, Yusuf, Kwazu, 2017; Ramasobona and Fatoki, 2017). Like most countries of the world, entrepreneurship has now become an antidote to unemployment in Nigeria. Nonetheless, the strategic tasks facing most of the Nigerian entrepreneurial managers have been how they can develop a highly competitive strategy to create and sustain competitive advantage within their competitive landscape. According to Porter $(1980,1985)$, the strategic source of sustainable competitive advantage among [entrepreneurial] firms can either be derived from each of these three generic competitive strategies low-cost provider strategy, product differentiation strategy, and focus strategy.

More importantly, sustainable competition, by developing competitive strategies mostly begins with firm's understanding about different strategic orientations (i.e., overall cost-leadership, differentiation, and focus) they need to pursue for them to realize their goals (Ortega, 2010). Meanwhile, existing 
studies on Porter's generic competitive strategies perspective have fuelled a debate on the strategic implications of how firms go about pursuing or developing any of the strategic orientation that determines whether a firm will be able to outperform its competitors in the industry. For instances, the empirical inquiry of Robinson and Pearce (1988), Dess and Davis (1984), and Hambrick (1983) support Porter's claim that a firm cannot efficiently pursue two strategic orientations - overall costleadership and differentiation concurrently.

While other scholarly studies such as Hill (1988), Jones and Butler (1988), Murray (1988), and Wright (1987) found that overall cost-leadership, differentiation, and focus strategies are not mutually exclusive and therefore, can be instantaneously pursued by firms. The empirical study of Spanos, Zaralis and Lioukas (2004) examines the influence of simultaneous pursuit of the combination of all the strategic orientations (i.e., overall cost-leadership, differentiation and focus). Also, abundant empirical studies have examined competitive strategies impacts on small businesses and entrepreneurial ventures' performance in different contexts (Acquaah and Agyapong, 2015; Bordean, Borza and Glaser-Segura 2011; Buul and Omundi, 2017; Chadamoyo and Dumbu, 2012; Jusoh and Parnell, 2008; Parnell and Köseoglu 2010; Kowo, Sabitu and Adegbite, 2018; Rosli, 2012; Uchegbulam, Akinyele and Ibidunni, 2015; Waidi, 2014), none has directly tested multiple criteria decision-making (MCDM) methods in handling several complex factors that determine how to identify the specific competitive strategy required for expected outcomes or business purposes (Wu, 2008), more especially among entrepreneurial firms in Nigeria. This creates the motivation and the research gap for this study. Again, most studies on competitive strategies as determinants of organizational performance and competitive advantage have some limitations. First, several studies have presumed that competitive strategy components are independent of one another and are not causally related. Second, most studies have also assumed that the weights of the evaluated components are identical. These limitations, therefore, pose relevant questions, - "what are the components of competitive strategies related to capturing, creating and sustaining competitive advantage among entrepreneurial managers in Nigeria?" and "which components of competitive strategies are the most influential components in sustaining competitive advantage among entrepreneurial ventures?

To fill this gap and to quantify the above concerns, this study contributes to the literature by using Decision Making Trial and Evaluation Laboratory (DEMATEL) technique which will provide better understandings on how various components of competitive strategies developed for capturing, creating and sustaining competitive advantage among entrepreneurial ventures affect each other and their final outcome.

To achieve the aims of this study, this article is subdivided into four sections. The first section provides a picture of the existing literature and theoretical background related to the study. The second section addresses research methods used in this study. The third section containes results and discu- 


\section{Dakare}

ssions. Finally, the fourth section provides concluding remarks.

\section{LITERATURE REVIEW}

From a theoretical perception, extant studies have established the efficacy of Porter's competitive strategies approach (Dess and Davis, 1984; Hambrick, 1983; Hawes and Crittenden, 1984) as the basis for sustainable competitive advantage within the competitive landscape. Meanwhile, Porter $(1980,1985)$ averred that a firm within a competitive industry could only achieve superior performance through the pursuit of a generic competitive strategy, this he however, defines as the development of low-cost provider, product differentiation, or focus approach to industry competition. As pointed out by Acquaah and Yasai-Ardekani (2008) sustainable competitive advantage through the three generic strategies can only be achievable seeing each of them as a different way of pursuing competitive advantage. Meaning that an organisation may choose to produce at the lowest cost compared to other competitors or can differentiate its products and sell them at a high premium price. Porter (1980, 1985) however, emphasized that low-cost provider and product differentiation strategies pursue competitive advantage in a wide-range of industry sectors, whereas focus strategies seek cost advantage (cost focus) or differentiation (differentiation focus) in a narrow fragment. Porter (1980, 1985) further maintained that organizations, therefore, need to make a choice amid one or the other of the generic competitive strategies to evade being "stuck in the middle".

Nonetheless, the empirical inquiry of Dess and Davis (1984), Miller (1988), and Spanos and Lioukas (2001) maintained that the low-cost provider strategy usually involves the efforts to achieve economies of scale, construction of modernization and automation of production processes, and capacity utilization; for differentiation strategy, it involves dimensions or components such as R\&D expenditure for product development, R\&D expenditure for process innovations, stress on being ahead of competition, and frequency of product innovations in order to develop innovation differentiation strategy and components such as innovations in marketing techniques, emphasis on marketing department organization, advertising expenditures and emphasis on strong sales force for the purpose of developing marketing differentiation strategy. Present study, however, derived and adapted the indices or components of assessing and measuring competitive strategy from the studies above as well which are listed in Table 1 (see Appendix-I).

As noted earlier in this paper, extant empirical studies have examined competitive strategies impacts on small businesses and entrepreneurial ventures' performance in different contexts. While the scope of some of these studies is based on the pursuit of generic competition and performance of SMEs, other studies reveal the convenience of combining the generic competitive strategies in explaining small business performance using statistical methodology such as cluster analysis, ANOVA, $t$-test as well as regression analysis. 
International Journal of Management, Economics and Social Sciences

For instance, Jusoh and Parnell (2008) employed descriptive statistics and ANOVA to determine the correlation between performance measures and competitive strategy within the Malaysian context. The result of the ANOVA analysis revealed that most of the manufacturing firms in Malaysia pursue innovation, production efficiency, and customer orientation, and low-price strategies since the environment seems to be stable and less uncertain. Parnell and Köseoglu (2010) also carried out a study on comparative analysis of competitive strategy and organizational performance between Turkey and the United States. It was found that Turkish respondents recounted higher levels of both innovation and cost-oriented strategy compared to their American counterparts. In the same vein, Bordean, Borza and Glaser-Segura (2011) conducted a comparative study on generic strategy within the hotel industry of Romania and USA using the factor analysis. The findings indicate that US hotels pursue a differentiation strategy and focus differentiation strategy while the Romania hotels pursue a cost leadership strategy.

The study of Rosli (2012) adopted the mean scores and $t$-tests to ascertain the dynamic aspect of competitive strategies among SMEs in Malaysia. The results revealed that SMEs in Malaysia emphasis more on the importance of firm management, human resource management, and marketing, and reasonable emphasis on total innovation. The empirical inquiry of Chadamoyo and Dumbu (2012) observed the influence of competitive strategy and business environment on Zimbabwean SMEs in Mucheke, using the qualitative research paradigm and descriptive survey design, revealed that innovation, cost and differentiation strategy are the key competitive strategies employed by Zimbabwean SMEs. Waidi (2014) used regression analysis to investigate the influence of competitive strategies and their performance with an emphasis on telecommunication companies in Nigeria. The results revealed that there is a significant connection between competitive strategy and customer satisfaction, retention and loyalty as well as positive impact amongst competitive strategy, its constituents, and performance of the sampled telecommunication companies. Similarly, Acquaah and Agyapong (2015) employed hierarchical multiple regression method to explain the connection between managerial and marketing capabilities in moderating the link between competitive strategy and performance of micro and small businesses (MSBs) in Ghana. The results of their study confirmed that the association between competitive strategy and performance of MSBs in Ghana are moderated by managerial capability and marketing capability.

Uchegbulam, Akinyele and Ibidunni (2015) also carried out a study on the influence of competitive strategy and performance of selected SMEs in Nigeria. The regression analysis was employed using a sample of 150 SMEs operators in Lagos, Nigeria. The results of the study revealed that there is a significant association between product customization and sales growth, product features and customer base, value-added products and revenue growth. For Buul and Omundi (2017), the results of their study on the association between competitive strategies and performance of SMEs in Kenya, using 


\section{Dakare}

Pearson's correlation method, analysis of variance (ANOVA) and multiple regression approach, reveal that cost leadership, differentiation, market focus, and strategic alliance have positive and significant impact on SMEs performance. Furthermore, Kowo, Sabitu and Adegbite (2018) conducted an empirical study on the influence of competitive strategies among SMEs' performance in Nigeria. A total of 125 SMEs' operators were surveyed and analyzed by using regression analysis. The findings of the study showed that cost leadership strategy has a significant effect on cost reduction of small and medium enterprises.

The aforementioned empirical review has demonstrated that studies have been carried out on impact of competitive strategies and firm performance, using different methodology, but there has not been any know study that mobilize fuzzy DEMATEL method in order to provide better understandings on how various components of competitive strategies developed for the purpose of capturing, creating and sustaining competitive advantage among Nigerian entrepreneurial ventures affect each other and their final outcome. This apparent gap inexorably snowballs to a knowledge gap that demands a scientific inquiry.

\section{METHODOLOGY}

This study employed a mixed method approach. As pointed out by Hoshmand (2003) this type of approach helps to provide the appropriate answers to research questions. The mixed method approach i.e., qualitative approach and quantitative approach was found to be the proper method to answer the research questions of this study. First, a qualitative approach was used to answer the research question "what are the components of competitive strategies related to capturing, creating and sustaining competitive advantage among entrepreneurial managers in Nigeria" with the aid of systematic literature review and second, the quantitative approach was used to answer the research question "which components of competitive strategies are the most influential components in sustaining competitive advantage among entrepreneurial ventures" by applying the DEMETAL technique.

Based on the reviewed literature on competitive studies by the author, the competitive strategies criteria were categorized into three major components (i.e., innovative differentiation, marketing differentiation and low-cost strategy) and 11 criteria for analysis (see Table1, Appendix-I). Also, these components and criteria were accredited by a focus group made up of qualified experts four of whom were professors of entrepreneurship and four entrepreneur experts. Meticulous discussions to gauge more precise ideas about competitive strategies were carried out by these experts. This panel of expert, therefore, provided their submissions and assessments on the basis of their expertise and preceding studies in the literature that the author has reviewed. Accordingly, the substantial viewpoints 
received from the discussions provide justifications to the results. Last, the DEMATEL approach was employed to identify the cause-and-effect relationships amongst competitive strategies measures.

\section{-DAMATEL}

The DEMATEL, as earlier mentioned in this paper, was advanced by the Battle Memorial Institute, Geneva and is the acronym for Decision Making Trial and Evaluation Laboratory. As pointed out by Lin et al. (2011), DEMATEL technique was initially designed to explain and understand structural relations in a complex system. According to Zhou, Huang, and Zhang (2011) it was designed to analyze complex problems connected to real life. For Ashtianipouri and Zandhessame (2015) DEMATEL is a technique used to elicit expert opinions to clarify the view of the contextual relationship that exists among variables.

Furthermore, it has been reaffirmed much of the prolific academic researchers in many fields (e.g., Ashtianipouri and Zandhessame, 2015; Lin et al., 2011; Raghuvanshi, Agrawal and Ghosh, 2017; Wu, 2008; Zhou et al., 2011) that DEMATEL as a technique is useful when it comes to causal analysis. This is because it enables studies to clear the connecting criteria of a system into cause-and-effect groups. Lin et al. (2011) further maintained that DEMATEL allows decision-makers to recognise criteria that are of a more significant effect. Thus, the author in this study adopted the DEMATEL approach since it can solve the causal relationship issues of developing competitive strategies required for expected outcomes among entrepreneurial managers in Nigeria, this, in turn, provides broad-minded options. The DEMATEL model construction processes are stated below:

Step 1: Generating the direct relationship matrix: To draw the inter-relationships among various variables, a group of subject-related experts that includes eight experts, four of whom were professors of entrepreneurship and four entrepreneur experts, were requested to form a pair-wise matrix of variables using the five-point scale to measure their responses $(0=$ no influence, $1=$ low influence, $2=$ medium influence, $3=$ high influence, and $4=$ extreme influence).

Step 2: Computing the average relation matrix: The average relationship was determined by calculating four direct relationship matrices X1, X2, X3, X4, from Equation 1 :

$$
\mathrm{A}=\frac{I}{K}\left(X_{1}+X_{2}+X_{3}+\cdots+X_{8}\right) \quad \text { Eq. (1) }
$$

where $\mathrm{K}$-expert $=8$ (see Table 2, Appendix-II).

Step 3: Computing the normalized direct relationship matrix (N): Through Equations (2) and (3) the normalized matrix $(\mathrm{N})$ was obtained.

$$
\mathrm{N}=a * A \quad \text { where } \mathrm{a}=\operatorname{Min}\left\{\frac{1}{\max \Sigma_{i}^{n} A}, \frac{1}{\max \Sigma_{j}^{n} A}\right\} \quad \text { Eq. (2) }
$$




\section{Dakare}

Hence, $\mathrm{a}=0.118$ (see Table 3, Appendix-III).

$$
\mathrm{N}=\boldsymbol{\sigma} * A \quad \text { Eq. (3) }
$$

Note: "a" represents constant, while "A" referrs to an element of average relationship matrix, the " $i$ represents an element of a row and " $j$ " however, represents an element of a column.

Step 4: Constructing the total-relation matrix: First, the normalized matrix was obtained and thereafter the total relationship matrix was calculated by:

$$
\mathrm{T}=\left(N(I-N)^{-1}\right) \quad \text { Eq. (4) }
$$

The "I" symbolizes identity matrix. (See Table 4, Appendix-IV)

Step 5: Calculating the cause and effect relationship: Through Equations (5) and (6) the cause and effect relationship table was determined.

The "R" means the sum of rows while " $C$ " means the sum of columns.

$$
\begin{aligned}
& R=\left(\sum_{j=1}^{n} T_{i j}\right)_{n x 1} \quad \text { Eq. (5) and (6) } \\
& C=\left(\sum_{i=1}^{n} T_{i j}\right)_{1 x n}
\end{aligned}
$$

\section{-Study Questionnaire}

The study research instrument comprised of three components (i.e., innovative differentiation, marketing differentiation, and low-cost strategies) and 11 items. Responses were tapped using 5points Likert scale. The items were adapted from Dess and Davis (1984), Miller (1988), and Spanos and Lioukas (2001) as earlier noted in this paper. The questionnaire was, however, modified, based on the considerable views received from the focus group discussions as more prior clarified in this study. Consequently, the questionnaire was subjected to validity testing through theoretical validity, nomological validity, and content validity.

\section{RESULTS}

The measures/criteria were ranked according to importance or influence on the basis of $(R+C)$ values as follows: $\mathrm{COM}>\mathrm{SSF}>\mathrm{RDPI}>\mathrm{MDO}>\mathrm{IMT}>\mathrm{RPI}>\mathrm{AD}>\mathrm{RDPD}>\mathrm{CU}>\mathrm{MAP}>\mathrm{EOS}$.

$(\mathrm{R}-\mathrm{C})$ values are used to rank causal on how competitive strategies are developed among entrepreneurial managers in Nigeria which are as follows (see Table 5, Appendix-V): IMT > MAP > 
$\mathrm{RDPI}>\mathrm{RPI}>\mathrm{RDPD}>\mathrm{EOS}>\mathrm{MDO}>\mathrm{SSF}>\mathrm{CU}>\mathrm{AD}>\mathrm{COM}$.

Setting a Threshold value $(\alpha)$ :

$$
\frac{4.705}{121}=0.039
$$

\section{DISCUSSION}

This study extends previous research (Acquaah and Agyapong, 2015; Bordean, Borza and GlaserSegura, 2011; Buul and Omundi, 2017; Chadamoyo and Dumbu, 2012; Jusoh and Parnell, 2008; Kowo, Sabitu and Adegbite, 2018; Parnell and Köseoglu, 2010; Rosli, 2012; Uchegbulam, Akinyele and Ibidunni, 2015; Waidi, 2014) and sheds more light on how entrepreneurial managers in Nigeria can better determine the cause-and-effect relationship on the components of competitive strategy by using the DEMATEL technique. The threshold value of 0.039 was set-up to sort out or rank the insignificant effects. According to Table 5, under innovative differentiation measures, this study found that in order for entrepreneurial managers in Nigeria to create and sustain competitive advantage within their competitive landscape, emphasis on being ahead of the competition and R\&D expenditure for process innovations were the two most important criteria based on first and second highest $(\mathrm{R}+\mathrm{C})$ values of 1.055 and 0.909 , respectively. Whereas, both R\&D expenditure for process innovations and rate of product innovations were in cause group based on their positive ( $R-C)$ values of 0.059 and 0.055, respectively. Emphasis on being ahead of the competition and R\&D expenditure for product development was in the effect group, given negative $(R-C)$ values of -0.111 and -0.003 , respectively. Also, considering the figures obtained in Table 5, emphasis on being ahead emerged the most critical factor when developing innovative differentiation strategies among entrepreneurial managers. This is because it has a direct influence on the other six criteria. This finding is in alignment with Roberts and Amit (2003) that see innovation as a means leading to competitive advantage and superior profitability. Meanwhile, the rate of product innovations has a direct impact on R\&D expenditure for product development. This finding is also supported by Hughes et al. (2010) that strongly argued that investments in R\&D strategy alone create the necessary strategic impetus to form innovation ambidexterity.

Furthermore, the results in Table 5 also show that for marketing differentiation measures, strong sales force and emphasis on market department organization were the two most important criteria that entrepreneurial managers will consider first when developing marketing differentiation strategies within the Nigerian business environment. This finding collaborates with the higher $(R+C)$ values of 0.919 for strong sales force and 0.892 for market department organization. Innovation in marketing technique was the only criterion that shows a positive net cause of $(R-C)$ value of 1.33 while an emphasis on 


\section{Dakare}

market department organization, advertising expenditures, and strong sales force were in the effect group based on the negative $(\mathrm{R}-\mathrm{C})$ values of $-0.034,-0.056$ and -0.043 respectively. Furthermore, the figures obtained in Table 5 also depicts that entrepreneurial managers, in pursuing marketing differentiation strategies as part of their competitive strategy, consider strong sales force as the most significant factor because it has a significant impact on the other three criteria as shown in this study. This finding is also supported by the studies carried out by Menguc and Auh (2006), Hult et al. (2005), and Hult and Ketchen (2001).

For the low-cost measures, capacity utilization was the most important criterion as it provides the highest $(R+C)$ value of 0.753 . This finding is also consistent with existing research of Miller (1986) and Porter (1980), these studies maintained that accurate demand forecasting combined with high capacity utilization by entrepreneurs would not only improve competitiveness but also lead to achieving competitive advantage. While, modernization and automation of the production process are next to it, which provides $(R+C)$ value of 0.739 . However, based on the $(R-C)$ value of 0.067 , modernization and automation of the production process was found to be the net cause and has a significant impact on the other two criteria. This finding is also supported by the extant research of Dess and Davis (1984), Miller (1988), and Spanos and Lioukas (2001) that emphasizes that technological advances capability reduces the cost of production.

\section{CONCLUSION}

This study explored how entrepreneurial managers in Nigeria can better identify and distinguish causeand-effect relationship amongst components of competitive strategies. The decisions to develop highly competitive strategies remain one of the main issues for managers within a competitive industry, more especially entrepreneurial ventures to improve their competitiveness and achieve competitive advantage. Meanwhile, previous studies have focused mostly on understanding the competitive strategies of an industry or a firm, but these studies did not provide enough analysis of the interactional relationship among the components of competitive strategy.

Consequently, this study applied the DEMATEL method to identify and describe the cause-andeffect relationship amongst the components of competitive strategies of entrepreneurial ventures which were classified into three components and eleven criteria after a review of the literature. The result of the study, however, implied that entrepreneurs and their management should concentrate on improving the innovative differentiation measure in the cause group. The findings reveal that in prioritizing the importance of criteria and cause-and-effect relationship among criteria under the three core components, this study found that emphasis on being ahead of the competition, strong sales force and $R \& D$ expenditure for process innovations were the most critical criteria. Furthermore, the result has 
International Journal of Management, Economics and Social Sciences

shown that emphasis on being ahead the competition is the most significant criterion in the adjustment of components of competitive strategies among entrepreneurial ventures in Nigeria. Therefore, developing a highly competitive strategy among entrepreneurial ventures, entrepreneurial managers will need first to develop the culture and attitude of being ahead of the competition.

\section{IMPLICATIONS}

The results of this study have shown that developing competitive strategies remain the most important source of creating and sustaining competitive advantage among entrepreneurial ventures. In terms of theoretical implications, emphasis on being ahead the competition among other criteria in the adjustment of components of competitive strategies serves as the "most" sources of sustainable competitive advantage among entrepreneurial ventures and small businesses. This result is acknowledged in previous research (e.g., Agyapong and Boamah, 2013; Acquaah, AmoakoGyampah and Jayaram, 2011; Spanos, Zaralis, and Lioukas, 2004). The findings also provide pivot why entrepreneurial managers and practitioners need to develop skills and ability that can help them to effectively identify, analyze, and exploit the external environment information better than their rivals through the learning gained experimentally and by holding strategic training courses in R\&D so as to become a pioneer or first-mover in the competitive industry (i.e., being first to initiate strategic moves such as new product development, technology, new-style components, new distribution channel, etc. in order to create an absolute cost advantage over rivals) which in turn, will improve the overall competitiveness of entrepreneurial ventures. The findings have clearly shown that when making decisions under the three core components of competitive strategies for entrepreneurial managers to develop a highly competitive strategy, more attention needs to be given to emphasis on being ahead of the competition, strong sales force and R\&D expenditure for process innovations. This finding, therefore, offers a clue as to why most of the entrepreneurial managers at first, try to develop the culture and attitude of being ahead of competition in line with their managerial propensities which have also helped them to create strategic moves that can give a high payoff in the midst of competitive pressures from rivals. As pointed out by Porter $(1980,1985)$, for a firm to achieve sustainable competitive advantage it must offer something different from its competitors.

From the practice perspective, the results further strengthen our consciousness on why entrepreneurial managers need to identify and prioritize the components of competitive strategies when they are taking decisions on formulating and developing a competitive strategy for their ventures since a component of competitive strategy by itself is seldom enough to win a sustainable competitive advantage. Consequently, when entrepreneurial managers in Nigeria, as well as others, are accessing the components of competitive strategies to formulate and develop a highly competitive strategy that 


\section{Dakare}

will create sustainable competitive advantage, it is imperative for them to consider the relative importance of criteria within each component of competitive strategy. For instance, emphasis on being ahead of the competition and R\&D expenditure for process innovations are the most critical criteria within the innovative differentiation component of competitive strategy. The ideal practice for entrepreneurial managers is to concentrate on how they can manage all three components of competitive strategy to formulate and develop a highly competitive strategy that improves their organizational performance and sustain competitive advantage.

\section{LIMITATIONS AND FUTURE DIRECTIONS}

This study also has some limitations. First, the proposed DEMATEL method in this study is applied to solve the determination of a complex and interactive competitive strategies issue of an entrepreneurial venture. Further research would need to provide an elaborate analysis of other sub-sectors or entrepreneurial ventures. Second, this study was carried out by only employing the opinions of eight experts; further research could be conducted by using robust statistical techniques to get more valid results. This study also suggests that in carrying out new research in the various sectors of small businesses and entrepreneurial ventures, there is a need to employ other multi-criteria decisionmaking methods such as the analytical hierarchy process (AHP), technique of order preference by similarity to ideal solution (TOPSIS), and interpretive structural modeling (ISM) for comparative analysis.

\section{REFERENCES}

Acquaah, M. \& Agyapong, A. (2015). The relationship between competitive strategy and firm performance in micro and small businesses in Ghana: The moderating role of managerial and marketing capabilities. Africa Journal of Management, 1(2): 172-193

Acquaah, M., Adjei, M. C. \& Mensa-Bonsu, I. F. (2008). Competitive strategy, environmental characteristics and performance in African emerging economies: Lessons from firms in Ghana. Journal of African Business, 9(1): 93-120.

Acquaah M., Amoako-Gyampah, K. \& Jayaram, J. (2011). Resilience in family and nonfamily firms: An examination of the relationships between manufacturing strategy, competitive strategy and firm performance. International Journal of Production Research, 49(18): 5527-5544

Acquaah, M. \& Yasai-Ardekani, M. (2008). Does the implementation of a combination competitive strategy yield incremental performance benefits? A new perspective from a transition economy in Sub-Saharan Africa. Journal of Business Research, $61,346-354$.

Agyapong, A., \& Boamah, R. (2013). Business strategies and competitive advantage of family hotel businesses in Ghana: The role of strategic leadership. Journal of Applied Business Research, 29 (2): 531-544.

Ashtianipouri, Z. \& Zandhessami, H. (2015). An integrated ISM-DEMATEL model for evaluation of technological innovation capabilities' impact on the competitiveness of small \& medium size enterprises (SMEs). Proceedings of PIC MET '15: Management ofthe Technology Age, 322-334.

Bordean, O. Borza, A. \& Glaser-Segura, D. (2011). A comparative approach of generic strategies within the hotel industry: Romania vs. USA. Management and Marketing Challenges for the Knowledge Society, 6(4): 501-514.

Buul, O.B. \& Omundi, R. (2017). An analysis of competitive strategies and performance of small and medium enterprises in Kenya: A case of Nairobi Central Business District. Journal of Business and Strategic Management, 2(2): 72-94.

Chadamoyo, P. \& Dumbu, E. (2012). Competitive strategy and business environment influencing performance of Small and Medium Enterprises in the Manufacturing sector: The case study of manufacturing firms in Mucheke light industry. European Journal of Business and Management, 4(10): 28-35.

Dess, G. \& Davis, P. (1984). Porter's (1980) generic strategies as determinants of strategic group membership and organizatio- 
nal performance. Academic of Management Journal, 27, 467-488.

Duru, I.U., Yusuf, A. \& Kwazu, V.C. (2017). Role of microfinance banks credit in the development of small and medium scale enterprises in Lokoja, Kogi State, Nigeria. Asian Journal of Economics, Business and Accounting, 5(3): 1-9.

Hambrick, D.C. (1983). High profit strategies in mature capital goods industries: A contingency framework. Academic Management Journal, 26, 687-707.

Hawes, J.M. \& Crittendon, W.F. (1984). A taxonomy of competitive retailing strategies. Strategic Management Journal, 5, 27587.

Hill, C.W.L. (1988). Differentiation versus low cost or differentiation and low cost: A contingency approach. Academic of Management Review, 13, 401-412.

Hoshmand, L. T. (2003). Can lessons of history and logical analysis ensure progress in psychological science? Theory and Psychology, 13(1): 39-44.

Hughes, M., Martin, S., Morgan, R. \& Robson, M. (2010). Realizing product-market advantage in high-technology international new ventures: The mediating role of ambidextrous innovation. Journal of International Marketing, 18(4): 1-21.

Hult, G. T. M. \& Ketchen, D. J. (2001). Does market orientation matter?: A test of the relationship between positional advantage and performance. Strategic Management Journal, 22(9): 899-906.

Hult, G. T. M., Ketchen, D. J. \& Slater, S. F. (2005). Market orientation and performance: An integration of disparate approaches. Strategic Management Journal, 26(12): 1173-1181.

Jones, G.R. \& Butler, J.E (1988). Costs, revenue, and business-level strategy. Academic of Management Review, 13, $201-213$.

Jusoh, R. \& Parnell, J.A. (2008). Competitive strategy and performance measurement in the Malaysian context. Management Decision, 46(1): 5-31.

Kowo, S., Sabitu, O. \& Adegbite, G. (2018). Influence of competitive strategies on corporate performance of small and medium enterprises: A case from Nigeria. Agricultural and Resource Economics: International Scientific E-Journal, 4(3): 14-33.

Li, J. J., Zhou, Z. K. \& Shao, A. T. (2009). Competitive position, managerial ties and profitability of foreign firms in China: An interactive perspective. Journal of International Business Studies, 40(2): 339-352.

Lin, Y.T., Yang, Y.H., Kang, J.S. \& Yu, H.C. (2011). Using DAMATEL method to explore the core competences and causal effect of the IC design service company: An empirical case study. Expert System with Applications, 38, 6262-6268.

Menguc, B. \& Auh, S. (2006). Creating a firm-level dynamic capability through capitalizing on market orientation and innovativeness. Journal of the Academy of Marketing Science, 34(1): 63-73.

Miller, A. \& Dess, G. G. (1993). Assessing Porter's (1980) model in terms of its generalizability, accuracy and simplicity. Journal of Management Studies, 30, 553-585.

Miller, D. F. (1988). Relating Porter's business strategies to environment and structure: analysis and performance implications. Academy of Management Journal 31, 280-308.

Miller D. F. (1986). Porter's (1980) Generic strategies and performance: An empirical examination with American data. Organization Studies, 7, 37-55

Murray, A.I. (1988). A contingency view of Porter's "Generic Strategies". Academic of Management Review, 13, 390-400.

Ortega, M.J.R. (2010). Competitive strategies and firm performance: Technological capabilities' moderating roles. Journal of Business Research, 63, 1273-1281.

Parnell, J.A. \& Köseoglu, M.A. (2010). A comparison of competitive strategy and organizational performance in Turkey and the United States. International Journal of Management \& Enterprise Development, 8(1): 46-61.

Porter, M. (1985). Competitive advantage: Creating and sustaining superior performance. New York: Simon and Schuster Trade.

Porter, M. (1980). Competitive strategy: Technical for analyzing industries and competitors. New York: The Free Press.

Raghuvanshi, J., Agrawal, R. \& Ghosh, P.K. (2017). Analysis of barriers to women entrepreneurship: The DEMATEL approach. The Journal of Entrepreneurship, 26(2): 220-238.

Ramasobona, M. \& Fatoki, O. (2017). Business attributes and marketing communication strategies of SMEs in South Africa. Journal of Economics and Behavioral Studies, 9(6): 90-97.

Roberts, P. W. \& Amit, R. (2003). The dynamics of innovative activity and competitive advantage: The case of Australian retail banking, 1981 to 1995. Organization Science, 14(2): 107-122.

Robinson, R. \& Pearce, J. (1988). Planned patterns of strategic behaviour and their relationship to business unit performance. Strategic Management Journal, 9(1): 43-60.

Rosli, M.M. (2012). Competitive strategy of Malaysian small and medium enterprises: An exploratory investigation. American International Journal of Contemporary Research, 2(1): 93-105.

Spanos, Y. \& Lioukas, S. (2001). An examination into the causal logic of rent generation: Contrasting Porter's competitive strategy framework and the resource-based perspective. Strategic Management Journal, 22(10): 907-934.

Spanos, Y. E., Zaralis, G. \& Lioukas, S. (2004). Strategy and industry effects on profitability: Evidence from Greece. Strategic Management Journal, 25, 139-165.

Uchegbulam, P., Akinyele, S. \& Ibidunni, A. (2015). Competitive strategy and performance of selected SMEs in Nigeria. International Conference on African Development Issues (CIJ-ICA DI) 2015: Social and Economic Models for Development Track.

Waidi, A. A. (2014). Competitive strategies and improved performance of selected Nigeria telecommunication companies. Journal of Entrepreneurship Management and Innovation, 10(4): 143-167.

Wright, P. (1987). A refinement of Porter's strategies. Strategic Management Journal, 8(1): 93-101.

Wu, W.W. (2008). Choosing knowledge management strategies by using a combined ANP and DEMATEL approach. Expert Systems with Applications 35, 828-835.

Zhou, Q., Huang, W. \& Zhang, Y. (2011). Identifying critical success factors in emergency management using a fuzzy DEMATEL method. Safety Science, 49(2): 243-252. 
Dakare

Appendix-I

\begin{tabular}{cc}
\hline Code & Measures \\
\hline $\mathbf{1 .}$ & Innovative Differentiation \\
RDPD & R\&D expenditure for product development \\
RDPI & R\&D expenditure for process innovations \\
COM & Emphasis on being ahead of competition \\
RPI & Rate of product innovations \\
\hline $\mathbf{2 .}$ & Marketing Differentiation \\
IMT & Innovations in marketing techniques \\
MDO & Emphasis on marketing department organization \\
AD & Advertising expenditures \\
SSF & Emphasis on strong sales force \\
\hline 3. & Low Cost \\
MAP & Modernization and automation of production processes \\
EOS & Efforts to achieve economies of scale \\
CU & Capacity utilization \\
\hline Soure Authors own &
\end{tabular}

Table 1. Measures of Competitive Strategy 
Appendix-II

\begin{tabular}{llllllllllll}
\hline & RDPD & RDPI & COM & RPI & IMT & MDO & AD & SSF & MAP & EOS & CU \\
\hline RDPD & 0 & 2.25 & 2.875 & 1.625 & 0 & 0 & 0 & 0 & 0 & 0 & 0 \\
RPDI & 2.375 & 0 & 2.75 & 2.375 & 0 & 0 & 0 & 0 & 0 & 0 & 0 \\
COM & 2.125 & 2.5 & 0 & 2.75 & 0 & 0 & 0 & 0 & 0 & 0 & 0 \\
RPI & 2.25 & 2.125 & 2.875 & 0 & 0 & 0 & 0 & 0 & 0 & 0 & 0 \\
IMT & 0 & 0 & 0 & 0 & 0 & 2.625 & 2.375 & 2.375 & 0 & 0 & 0 \\
MDO & 0 & 0 & 0 & 0 & 1.75 & 0 & 2.125 & 2.625 & 0 & 0 & 0 \\
AD & 0 & 0 & 0 & 0 & 2 & 2 & 0 & 2.125 & 0 & 0 & 0 \\
SSF & 0 & 0 & 0 & 0 & 2.125 & 2.25 & 2.25 & 0 & 0 & 0 & 0 \\
MAP & 0 & 0 & 0 & 0 & 0 & 0 & 0 & 0 & 0 & 2.5 & 2.75 \\
EOS & 0 & 0 & 0 & 0 & 0 & 0 & 0 & 0 & 2.25 & 0 & 2.5 \\
CU & 0 & 0 & 0 & 0 & 0 & 0 & 0 & 0 & 2.375 & 2.375 & 0 \\
\hline SOUn
\end{tabular}

Source: Author's own

Table 2. Direct Influence Matrix 
Dakare

Appendix-III

\begin{tabular}{|c|c|c|c|c|c|c|c|c|c|c|c|}
\hline & RDPD & RDPI & COM & RPI & IMT & MDO & AD & SSF & МАP & EOS & $\mathbf{C U}$ \\
\hline RDPD & 0 & .266 & .339 & .192 & 0 & 0 & 0 & 0 & 0 & 0 & 0 \\
\hline RDPI & .28 & 0 & .325 & .28 & 0 & 0 & 0 & 0 & 0 & 0 & 0 \\
\hline COM & .251 & .295 & 0 & .325 & 0 & 0 & 0 & 0 & 0 & 0 & 0 \\
\hline RPI & .266 & .251 & .339 & 0 & 0 & 0 & 0 & 0 & 0 & 0 & 0 \\
\hline IMT & 0 & 0 & 0 & 0 & 0 & .309 & .28 & .280 & 0 & 0 & 0 \\
\hline MDO & 0 & 0 & 0 & 0 & .207 & 0 & .251 & .309 & 0 & 0 & 0 \\
\hline AD & 0 & 0 & 0 & 0 & .236 & .236 & 0 & .251 & 0 & 0 & 0 \\
\hline SSF & 0 & 0 & 0 & 0 & .251 & .266 & .266 & 0 & 0 & 0 & 0 \\
\hline МАР & 0 & 0 & 0 & 0 & 0 & 0 & 0 & 0 & 0 & .295 & .325 \\
\hline EOS & 0 & 0 & 0 & 0 & 0 & 0 & 0 & 0 & .266 & 0 & .295 \\
\hline $\mathbf{C U}$ & 0 & 0 & 0 & 0 & 0 & 0 & 0 & 0 & .28 & .28 & 0 \\
\hline
\end{tabular}

Table 3. Direct Relation Matrix 
Appendix-IV

\begin{tabular}{|c|c|c|c|c|c|c|c|c|c|c|c|}
\hline & RDPD & RDPI & COM & RPI & IMT & MDO & $\overline{A D}$ & SSF & MAP & EOS & $\overline{\mathrm{CU}}$ \\
\hline RDPD & -.150 & .200 & .302 & .067 & 0 & 0 & 0 & 0 & 0 & 0 & 0 \\
\hline RDPI & .214 & -.181 & .239 & .212 & 0 & 0 & 0 & 0 & 0 & 0 & 0 \\
\hline COM & .161 & .246 & -.237 & .302 & 0 & 0 & 0 & 0 & 0 & 0 & 0 \\
\hline RPI & .197 & .160 & .279 & -.173 & 0 & 0 & 0 & 0 & 0 & 0 & 0 \\
\hline IMT & 0 & 0 & 0 & 0 & -.150 & .256 & .207 & .191 & 0 & 0 & 0 \\
\hline MDO & 0 & 0 & 0 & 0 & .127 & -.155 & .181 & .276 & 0 & 0 & 0 \\
\hline AD & 0 & 0 & 0 & 0 & .190 & .162 & -.143 & .184 & 0 & 0 & 0 \\
\hline SSF & 0 & 0 & 0 & 0 & .204 & .200 & .204 & -.170 & 0 & 0 & 0 \\
\hline MAP & 0 & 0 & 0 & 0 & 0 & 0 & 0 & 0 & -.152 & .256 & .299 \\
\hline EOS & 0 & 0 & 0 & 0 & 0 & 0 & 0 & 0 & .230 & -.141 & .262 \\
\hline $\mathbf{C U}$ & 0 & 0 & 0 & 0 & 0 & 0 & 0 & 0 & .258 & .248 & -.157 \\
\hline
\end{tabular}

Table 4. Total Relationship Matrix 
Dakare

Appendix-V

\begin{tabular}{lrrrr}
\hline & $\mathbf{R}$ & $\mathbf{C}$ & $\mathbf{R}+\mathbf{C}$ & $\mathbf{R}-\mathbf{C}$ \\
\hline RDPD & 0.419 & 0.422 & 0.841 & -0.003 \\
RDPI & 0.484 & 0.425 & 0.909 & 0.059 \\
COM & 0.472 & 0.583 & 1.055 & -0.111 \\
RPI & 0.463 & 0.408 & 0.871 & 0.055 \\
IMT & 0.504 & 0.371 & 0.875 & 1.33 \\
MDO & 0.429 & 0.463 & 0.892 & -0.034 \\
AD & 0.393 & 0.449 & 0.842 & -0.056 \\
SSF & 0.438 & 0.481 & 0.919 & -0.043 \\
MAP & 0.403 & 0.336 & 0.739 & 0.067 \\
EOS & 0.351 & 0.363 & 0.714 & -0.012 \\
CU & 0.349 & 0.404 & 0.753 & -0.055 \\
\hline Source: Author's own & & & & \\
\hline
\end{tabular}

Table 5. Cause and Effect Relationship Matrix 